\title{
Radical-induced chemistry from VUV photolysis of interstellar ice analogues containing formaldehyde
}

\author{
Teddy Butscher, Fabrice Duvernay, Grégoire Danger, and Thierry Chiavassa
}

\begin{abstract}
PIIM, UMR 7345, Aix-Marseille Université, Avenue Escadrille Normandie-Niemen, 13397 Marseille, France
e-mail: fabrice.duvernay@univ-amu.fr
\end{abstract}

Received 5 February 2016 / Accepted 16 June 2016

\begin{abstract}
Surface processes and radical chemistry within interstellar ices are increasingly suspected to play an important role in the formation of complex organic molecules (COMs) observed in several astrophysical regions and cometary environments. We present new laboratory experiments on the low-temperature solid state formation of complex organic molecules - glycolaldehyde, ethylene glycol, and polyoxymethylene - through radical-induced reactivity from VUV photolysis of formaldehyde in water-free and water-dominated ices. Radical reactivity and endogenous formation of COMs were monitored in situ via infrared spectroscopy in the solid state and post photolysis with temperature programmed desorption (TPD) using a quadripole mass spectrometer. We show the ability of free radicals to be stored when formed at low temperature in water-dominated ices, and to react with other radicals or on double bonds of unsaturated molecules when the temperature increases. It experimentally confirms the role of thermal diffusion in radical reactivity. We propose a new pathway for formaldehyde polymerisation induced by $\mathrm{HCO}$ radicals that might explain some observations made by the Ptolemy instrument on board the Rosetta lander Philae. In addition, our results seem to indicate that $\mathrm{H}$-atom additions on $\mathrm{H}_{2} \mathrm{CO}$ proceed preferentially through $\mathrm{CH}_{2} \mathrm{OH}$ intermediate radicals rather than the $\mathrm{CH}_{3} \mathrm{O}$ radical.
\end{abstract}

Key words. astrochemistry - molecular data - methods: laboratory: solid state - ISM: molecules

\section{Introduction}

Complex organic molecules (COMs) are becoming increasingly important in astrophysical studies (Herbst \& Van Dishoeck 2009) since they are readily detected in a wider range of astrophysical environments (hot cores, prestellar cores, etc.) with the technological advances of telescope arrays (Coutens et al. 2015; Calcutt et al. 2014; Biver et al. 2014; Jørgensen et al. 2012; Beltrán et al. 2009; Cernicharo et al. 2012; Bacmann et al. 2016). It was originally assumed they were primarily formed as a result of gas phase chemistry. However, networks of gas phase processes via neutral-neutral and/or molecule reactions failed to reproduce the abundance of complex organics observed toward protostellar cores. In order to increase the production rates of COMs in such environments, astrochemical modelling started to incorporate radical-radical reactions on interstellar grains. With it, glycolaldehyde (GA), ethylene glycol (EG), methyl formate $(\mathrm{MF})$, and other COMs are all readily formed within icy mantles of the interstellar grains.

Thanks to the ISO (Gibb et al. 2004, 2000) and the Spitzer space telescopes (Boogert et al. 2008), we had the confirmation that interstellar grains are coated with an icy mantle consisting mainly of water $\left(\mathrm{H}_{2} \mathrm{O}\right)$ followed by methanol $\left(\mathrm{CH}_{3} \mathrm{OH}\right)$, carbon monoxide $(\mathrm{CO})$, carbon dioxide $\left(\mathrm{CO}_{2}\right)$, methane $\left(\mathrm{CH}_{4}\right)$, ammonia $\left(\mathrm{NH}_{3}\right)$, and formaldehyde $\left(\mathrm{H}_{2} \mathrm{CO}\right)$ holding a thickness of a few hundred nanometers. These simple molecules serve as precursors of COMs as demonstrated by laboratory experiments (Abou Mrad et al. 2016; Maity et al. 2015; Henderson \& Gudipati 2015; Öberg et al. 2009; Hudson \& Moore 2000). When ice analogues that mimic interstellar composition are exposed in the laboratory, at low temperatures (around $10 \mathrm{~K}$ ), to either cosmic radiation or VUV photons, a large variety of molecular species initiated by radical reactions can be generated within the ice mantle (Maity et al. 2015; Henderson \& Gudipati 2015). One of the most fundamental processes of ice photochemistry is photodissociation of the water molecule and the subsequent formation of $\mathrm{H}$-atoms, $\mathrm{OH}$ radicals, and hydrogen molecules (Yabushita et al. 2008; Gerakines et al. 1996). These UV photochemistry simulations in the laboratory also provide powerful tools for the interpretation of astronomical observations in measuring UV destruction cross-section as well as photochemical processes for use in astrochemical models (Gerakines et al. 1996; Martín-Doménech et al. 2016).

Radicals can also be formed from softer processes such as hydrogenation reaction. Solid state formation of complex organic molecules - glycoaldehyde and ethylene glycol - has been reported through recombination of free radicals formed via $\mathrm{H}$-atom addition/abstraction on $\mathrm{CO}$ and $\mathrm{H}_{2} \mathrm{CO}$ (Fedoseev et al. 2015; Chuang et al. 2016; Butscher et al. 2015), which means that radical formation can also start at the beginning of the $\mathrm{CO}$ freeze-out stage in the evolution of dark interstellar clouds even when energetic external UV radiation is not present (Chuang et al. 2016; Butscher et al. 2015). Consequently, the role of surface processes and radical chemistry within interstellar/cometary ices is becoming increasingly important to account for the abundances of COMs observed in several astrophysical regions including dark molecular clouds leading to an increase of experimental and theoretical studies dedicated to their molecular formation pathways (Bennett \& Kaiser 2007; Wang \& Bowie 2010; Maity et al. 2015). However, most of these studies do not detect the intermediate species, which prevents them from confidently determining the formation mechanism of COMs in ice. Matrix isolation techniques have been successfully used to study the formation mechanism of glycolaldehyde and ethylene glycol 
from radical recombination (Butscher et al. 2015). They demonstrated that $\mathrm{HCO}$ and $\mathrm{CH}_{2} \mathrm{OH}$ radicals can directly yield glycolaldehyde and ethylene glycol:

$$
\begin{aligned}
& \mathrm{HCO}+\mathrm{CH}_{2} \mathrm{OH} \rightarrow \mathrm{HC}(\mathrm{O}) \mathrm{CH}_{2} \mathrm{OH} \\
& \mathrm{CH}_{2} \mathrm{OH}+\mathrm{CH}_{2} \mathrm{OH} \rightarrow \mathrm{HOCH}_{2} \mathrm{CH}_{2} \mathrm{OH} .
\end{aligned}
$$

In this contribution, we investigate the radical reactivity triggered by Lyman- $\alpha$ photons on formaldehyde ${ }^{12} \mathrm{C}$ and ${ }^{13} \mathrm{C}$ isotopologues in astrophysically relevant conditions (i.e. in waterfree and water-dominated ices at $13 \mathrm{~K}$ ). We show solid state formation of complex organic molecules - glycolaldehyde, ethylene glycol, and polyoxymethylene - through radicalinduced reactivity. The astrophysical implications of these results are also presented.

\section{Experimental}

Formaldehyde ${ }^{12} \mathrm{C}$ and ${ }^{13} \mathrm{C}$ were purchased as a polymer (paraformaldehyde) from Sigma Aldrich (99\% purity) and were heated to about $90{ }^{\circ} \mathrm{C}$ to produce the gas-phase monomer. Glycolaldehyde (GA) was purchased as a dimer from Sigma Aldrich (99.95\% of purity) and heated under vacuum to about $80{ }^{\circ} \mathrm{C}$ to produce the gas-phase monomer. Water and methanol (Aldrich $99.9 \%$ purity) are doubly distilled under vacuum before injection. Ethylene glycol (EG) and methanol (99.95\% purity) were purchased from Sigma Aldrich. The gaseous samples are prepared in a primary vacuum pumped mixing line at room temperature. They are then deposited onto a gold-plated metal surface cooled to $13 \mathrm{~K}$ at a rate of $0.1 \mathrm{mbars}^{-1}\left(8 \mu\right.$ mole s$\left.^{-1}\right)$. Glycolaldehyde and ethylene glycol solid films can be obtained by directly dosing them onto the sample holder in order to get spectroscopic references.

All experiments described were performed under highvacuum conditions using the AHIIA set-up that has been described in detail by Butscher et al. (2015). The background pressure in the chamber is about $10^{-8} \mathrm{mbar}$ at $13 \mathrm{~K}$. Accessible temperatures range from $12 \mathrm{~K}$ to $310 \mathrm{~K}$. The temperature is controlled using a model 21 CTI cold head, a resistive heater, and a Lakeshore 331 temperature controller.

The VUV source has been described in detail by Butscher et al. (2015). Briefly, VUV photons are generated from a microwave induced $\mathrm{H}_{2}$ plasma (Opthos instruments). The $\mathrm{H}_{2}$ plasma spectrum is dominated by Lyman-alpha photons at $121.6 \mathrm{~nm}$. The VUV flux is transmitted from the plasma chamber to the vacuum chamber through a $\mathrm{MgF}_{2}$ window. The photon flux has been measured using the $\mathrm{O}_{2} \rightarrow \mathrm{O}_{3}$ actinometry method (Cottin et al. 2003) about $2.5 \times 10^{13}$ photons $\mathrm{cm}^{-2} \mathrm{~s}^{-1}$, which is $10^{10}$ times higher than the UV secondary flux in dense molecular clouds. The typical ice thickness in our experiments is about $0.1 \mu \mathrm{m}$, which is comparable to the UV penetration at Lyman- $\alpha$ (Cottin et al. 2003; Gerakines et al. 1996). Thus, such thin layers ensure that all ice samples are optically thin throughout the wavelength range.

The ice diagnostics are performed by using a Bruker Tensor 27 FTIR spectrometer with MCT detector. Infrared spectra are recorded in reflection-absorption mode between 4000 and $600 \mathrm{~cm}^{-1}$. Each spectrum is averaged over 20 scans with a $0.5 \mathrm{~cm}^{-1}$ resolution, except for the background averaged over one hundred scans with the same resolution. The column densities $(\mathcal{N})$ in molec $\mathrm{cm}^{-2}$ are measured using $(\mathcal{N})=\frac{\int 2.3 \mathrm{Abs}(\nu) \mathrm{d} v}{2 \mathcal{A}}$, where $\int \operatorname{Abs}(v) \mathrm{d} v$ is the integrated intensity of an infrared band in $\mathrm{cm}^{-1}$, and $\mathcal{A}$ is the intrinsic band strength. The amount of

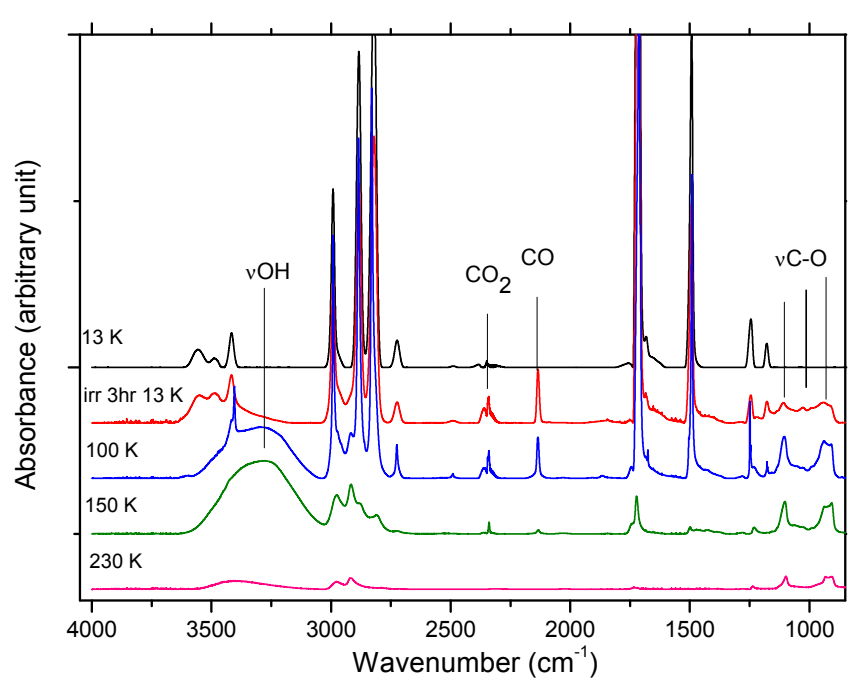

Fig. 1. Infrared spectra of $\mathrm{H}_{2} \mathrm{CO}$ ice at $13 \mathrm{~K}$ after deposition; at $13 \mathrm{~K}$ after $3 \mathrm{~h}$ of VUV photolysis; and then heated to $100 \mathrm{~K}, 150 \mathrm{~K}$, and $230 \mathrm{~K}$.

GA is obtained from the band at around $1750 \mathrm{~cm}^{-1}(\mathcal{A}=2.6 \times$ $10^{-17} \mathrm{~cm}$ molecule ${ }^{-1}$ ) and the amount of EG is obtained from the bands at around $1080 \mathrm{~cm}^{-1}$ with a band strength of $\mathcal{A}=3.9 \times$ $10^{-18} \mathrm{~cm} \mathrm{molecule}^{-1}$ (Hudson et al. 2005). Finally, the amount of methanol is obtained from the band at around $1025 \mathrm{~cm}^{-1}$ with a band strength of $\mathcal{A}=1.8 \times 10^{-17} \mathrm{~cm} \mathrm{molecule}^{-1}$ (Kerkhof et al. 1999).

Mass spectra are monitored using a RGA quadrupole mass spectrometer (MKS Microvision-IP plus) as the products desorb during the controlled temperature ramp. The ionisation source is a $70 \mathrm{eV}$ impact electronic source and the mass spectra are recorded between 1 and 100 amu in a full scan. A ramp of $4 \mathrm{~K} \mathrm{~min}^{-1}$ is applied while the ion current is recorded to obtain a full temperature programmed desorption (TPD) profile, relative to various products.

\section{Results}

\subsection{VUV photolysis of pure $\mathrm{H}_{2} \mathrm{CO}$ solid film}

The mid-IR spectrum of the unirradiated $\mathrm{H}_{2} \mathrm{CO}$ sample at $13 \mathrm{~K}$ is shown in Fig. 1. Infrared band positions of $\mathrm{H}_{2}^{12} \mathrm{CO}$ and $\mathrm{H}_{2}^{13} \mathrm{CO}$ as well as their corresponding vibrational assignments are listed in Table 1. After $3 \mathrm{~h}$ of VUV photolysis, $30 \%$ of the formaldehyde has been consumed and many new features appear (Fig. 1). Its time decay is fitted with a first-order kinetic rate. The corresponding kinetic constant is found to be $k=1.87 \times 10^{-4} \mathrm{~s}^{-1}$. Knowing that $k=\sigma_{\text {photo }} . \phi_{\mathrm{UV}}$, the corresponding photodissociation cross-section can be estimated to be $\sigma_{\text {photo }}=7.5 \times$ $10^{-18} \mathrm{~cm}^{-2}$ with our photon fluence (see Sect. 2). This value is close to the one previously reported by Gerakines et al. (1996) $6.2 \times 10^{-18} \mathrm{~cm}^{-2}$. The new bands that are observed during the photolysis are listed in Table 2 for both ${ }^{12} \mathrm{C}$ and ${ }^{13} \mathrm{C}$ experiments. The most striking features located in the $\mathrm{C}-\mathrm{O}$ stretching region at 912,945 , and $991 \mathrm{~cm}^{-1}$ are assigned to the formaldehyde polymer, polyoxymethylene (POM; Schutte et al. 1993; Table 2 and Fig. 2). In the $2400-2000 \mathrm{~cm}^{-1}$ range, $\mathrm{CO}_{2}$ and $\mathrm{CO}$ are easily assigned from the features observed at 2343 and $2136 \mathrm{~cm}^{-1}$ respectively (Gerakines et al. 1996). These confirm previous results on pure formalydehyde photolysis at $10 \mathrm{~K}$ (Gerakines et al. 1996). The small band observed at $1751 \mathrm{~cm}^{-1}$ is attributed to glycolaldehyde (GA; Hudson et al. 2005; Table 2 and Fig. 2). 
T. Butscher et al.: Radical-induced chemistry from VUV photolysis of interstellar ice analogues containing formaldehyde

Table 1. Positions and integrated band strengths of $\mathrm{H}_{2} \mathrm{CO}$ and the $\mathrm{H}_{2}^{13} \mathrm{CO}$ isotopologue at $13 \mathrm{~K}$.

\begin{tabular}{|c|c|c|c|c|c|c|}
\hline \multicolumn{4}{|c|}{ Position $\left(\mathrm{cm}^{-1}\right)$} & \multirow[t]{3}{*}{$A\left(\mathrm{~cm} \mathrm{molec}{ }^{-1}\right)^{a}$} & \multirow[t]{3}{*}{ Mode $^{a}$} & \multirow[t]{3}{*}{ Label $^{a}$} \\
\hline \multicolumn{2}{|c|}{ pure } & \multicolumn{2}{|c|}{ in water } & & & \\
\hline${ }^{12} \mathrm{C}$ & ${ }^{13} \mathrm{C}$ & ${ }^{12} \mathrm{C}$ & ${ }^{13} \mathrm{C}$ & & & \\
\hline 2991 & 2957 & 2993 & 2959 & $3.2 \times 10^{-18}$ & & $v_{2}+v_{6}$ \\
\hline 2885 & 2860 & 2883 & 2860 & $4.7 \times 10^{-18}$ & $\nu \mathrm{CH}_{2 a s}$ & $v_{5}$ \\
\hline 2821 & 2819 & 2826 & 2817 & $1.3 \times 10^{-17}$ & $v \mathrm{CH}_{2 s}$ & $v_{1}$ \\
\hline 2724 & 2717 & 2723 & 2715 & 1 & & $v_{2}+v_{4}^{b}$ \\
\hline 1716 & 1682 & 1715 & 1678 & $1.6 \times 10^{-17}$ & $v \mathrm{CO}$ & $v_{2}$ \\
\hline 1492 & 1492 & 1496 & 1494 & $5.1 \times 10^{-18}$ & $\delta \mathrm{CH}_{2}$ & $v_{3}$ \\
\hline 1244 & 1235 & 1247 & 1237 & $1.5 \times 10^{-18}$ & $\rho \mathrm{CH}_{2}$ & $v_{6}$ \\
\hline 1178 & 1167 & 1178 & 1167 & $7.2 \times 10^{-19}$ & $\omega \mathrm{CH}$ & $v_{4}$ \\
\hline
\end{tabular}

Notes. $v$ : stretching; $\delta$ : bending; $\rho$ : rocking; $\omega$ : wagging. ${ }^{(a)}$ From Bouilloud et al. $(2015) ;{ }^{(b)}$ tentative.

Table 2. New bands observed during the VUV photolysis of solid $\mathrm{H}_{2} \mathrm{CO}$ at $13 \mathrm{~K}$.

\begin{tabular}{|c|c|c|c|c|c|}
\hline \multicolumn{2}{|c|}{$v\left(\mathrm{~cm}^{-1}\right)$} & \multirow[t]{2}{*}{ Mode } & \multirow{2}{*}{$\begin{array}{c}A \\
\left(\mathrm{~cm} \mathrm{molec}^{-1}\right)\end{array}$} & \multirow[t]{2}{*}{ Molecule } & \multirow[t]{2}{*}{ Ref } \\
\hline${ }^{12} \mathrm{C}$ & ${ }^{13} \mathrm{C}$ & & & & \\
\hline 2343 & 2275 & $v(\mathrm{CO})$ & $7.6 \times 10^{-17}$ & $\mathrm{CO}_{2}$ & $a$ \\
\hline 2136 & 2087 & $v(\mathrm{CO})$ & $1.1 \times 10^{-17}$ & $\mathrm{CO}$ & $b$ \\
\hline 1846 & 1804 & $v(\mathrm{C}=\mathrm{O})$ & $2.1 \times 10^{-17}$ & $\mathrm{HCO}$ & $c$ \\
\hline 1751 & 1721 & $v(\mathrm{C}=\mathrm{O})$ & $2.6 \times 10^{-17}$ & GA & $d$ \\
\hline 1217 & 1205 & $? ?$ & & POM & $e$ \\
\hline 1109 & 1095 & $v(\mathrm{C}-\mathrm{O})$ & $9.7 \times 10^{-18}$ & POM & $e$ \\
\hline 1075 & 1058 & $v(\mathrm{C}-\mathrm{O})$ & $3.9 \times 10^{-18}$ & EG & $d$ \\
\hline 1046 & $\mathrm{Xx}$ & $v(\mathrm{C}-\mathrm{O})$ & $3.9 \times 10^{-18}$ & EG & $d$ \\
\hline 1027 & 1006 & $v(\mathrm{C}-\mathrm{O})$ & $1.8 \times 10^{-17}$ & $\mathrm{CH}_{3} \mathrm{OH}$ & $f$ \\
\hline 991 & 970 & $v(\mathrm{C}-\mathrm{O})$ & - & POM & $e$ \\
\hline 945 & 919 & $v(\mathrm{C}-\mathrm{O})$ & $3.0 \times 10^{-17 g}$ & POM & $e$ \\
\hline 912 & 887 & $v(\mathrm{C}-\mathrm{O})$ & $3.0 \times 10^{-17 g}$ & POM & $e$ \\
\hline
\end{tabular}

Notes. $v$ : stretching; $\delta$ : bending; $\rho$ : rocking; $\omega$ : wagging. ${ }^{(a)}$ Bouilloud et al. (2015); ${ }^{(b)}$ Gerakines et al. (1996); (c) Bennett \& Kaiser (2007); (d) Hudson et al. (2005); ${ }^{(e)}$ Schutte et al. (1993); ${ }^{(f)}$ Kerkhof et al. (1999); ${ }^{(g)}$ since the lengths of the polymer chains are unknown, the strengths of the indicated bands are given per carbon atom (Schutte et al. 1993).

Ethylene glycol (EG) is assigned from its characteristic bands located at 1089 and $1046 \mathrm{~cm}^{-1}$ (Hudson et al. 2005) that appear in the vicinity of the $\mathrm{C}-\mathrm{O}$ stretching modes of POM at $1109 \mathrm{~cm}^{-1}$ and methanol at $1027 \mathrm{~cm}^{-1}$, respectively (Table 2 and Fig. 2). It has to be noted that characteristic bands of GA and EG are low in intensities compared to those of POM attesting to the lower amount of these two compounds. This may explain why these two compounds were not reported in previous studies related to formaldehyde photolysis at $10 \mathrm{~K}$ (Gerakines et al. 1996). The infrared spectra of pure GA, EG, POM, and methanol are shown in Fig. 2 as references and can be directly compared with the solid film obtained after photolysis (top spectrum).

The small band at $1846 \mathrm{~cm}^{-1}$ is attributed to solid HCO radical (Milligan \& Jacox 1969; Hudson et al. 2005). In our experimental conditions, $\mathrm{HCO}$ is the only radical species that can be safely assigned. The final abundances of products observed after $3 \mathrm{~h}$ of pure formaldehyde photolysis are listed in Table 3. The dominant product is polyoxymethylene, which represents $72 \%$ of consumed formaldehyde (Table 3). Coming next is carbon monoxide and methanol with relative abundances of $18.5 \%$ and

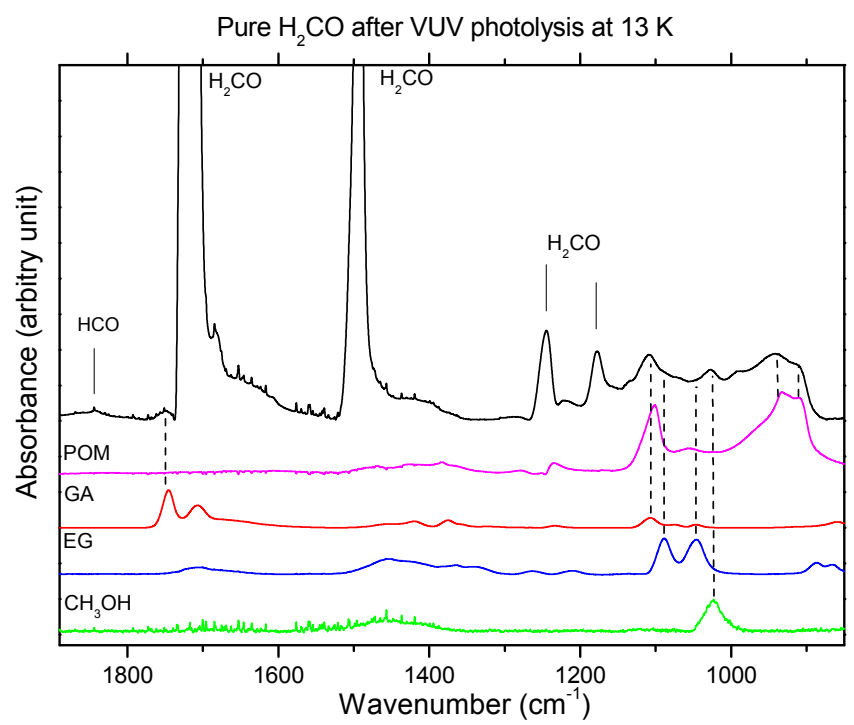

Fig. 2. Infrared spectrum of $\mathrm{H}_{2} \mathrm{CO}$ ice at $13 \mathrm{~K}$ recorded after $3 \mathrm{~h}$ of VUV irradiation compared with infrared reference spectra of polyoxymethylene (POM), glycoaldehyde (GA), ethylene glycol (EG), and methanol.

$8 \%$, respectively. The other compounds are observed with lower abundances $(<1 \%)$. These results suggest that the dominant reaction is the formaldehyde polymerisation initiated by the observed HCO radical (Hiraoka et al. 2005; Gerakines et al. 1996). Polymerisation initiated by other radicals such as $\mathrm{CH}_{2} \mathrm{OH}$ cannot be excluded since both glycolaldehyde and ethylene glycol are observed after photolysis (Butscher et al. 2015). The nondetection of the $\mathrm{CH}_{2} \mathrm{OH}$ radical in our experiments, does not necessarily mean that does not form since its strongest absorption band at $1195 \mathrm{~cm}^{-1}$ (Maity et al. 2015; Jacox \& Milligan 1973) can easily be overlapped by the wagging C-H mode of formaldehyde around $1180 \mathrm{~cm}^{-1}$.

After VUV photolysis at $13 \mathrm{~K}$, the sample has been grad-

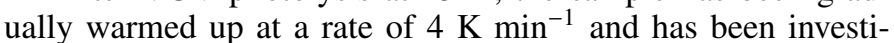
gated by infrared and mass spectroscopies. Above $13 \mathrm{~K}$ and until $100 \mathrm{~K}$, the characteristic bands of POM grow while the bands of formaldehyde and $\mathrm{HCO}$ decrease, attesting to the formaldehyde polymerisation initiated by HCO radicals (Fig. 1). Desorption of formaldehyde is observed in our experimental conditions between 110 and $160 \mathrm{~K}$ (Fig. 1). After $200 \mathrm{~K}$, the bands related to POM start to decrease and are almost undetectable after $250 \mathrm{~K}$ (Fig. 1). This is due to sublimation of POM and to 


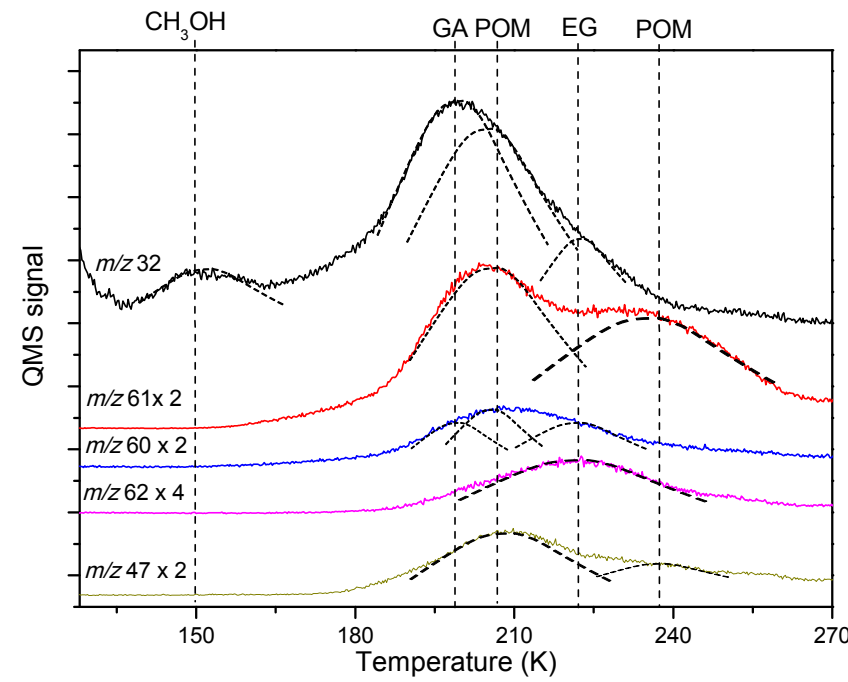

Fig. 3. TPD spectra $\left(4 \mathrm{~K} \mathrm{~min}^{-1}\right)$ of the photolysed $\mathrm{H}_{2} \mathrm{CO}$ solid film experiment. Only the relevant $m / z$ values are shown.

Table 3. Overview of the performed experiments and abundances of the formed species of VUV photolysis at $13 \mathrm{~K}$ of pure $\mathrm{H}_{2} \mathrm{CO}$ and a $\mathrm{H}_{2} \mathrm{O}: \mathrm{H}_{2} \mathrm{CO}$ ice mixture.

\begin{tabular}{|c|c|c|c|c|}
\hline \multicolumn{5}{|c|}{ VUV photolysis of $\mathrm{H}_{2} \mathrm{CO}$ ice } \\
\hline & \multicolumn{2}{|c|}{ Pure $\mathrm{H}_{2} \mathrm{CO}$} & \multicolumn{2}{|l|}{$\mathrm{H}_{2} \mathrm{O}: \mathrm{H}_{2} \mathrm{CO}$} \\
\hline Species & $N\left(\right.$ molec $\left.\mathrm{cm}^{-2}\right)$ & $(\%)$ & $N\left(\right.$ molec $\left.\mathrm{cm}^{-2}\right)$ & $(\%)$ \\
\hline $\mathrm{CO}$ & $5 \times 10^{16}$ & 18.5 & $6 \times 10^{16}$ & 40 \\
\hline $\mathrm{CO}_{2}$ & $1.6 \times 10^{15}$ & 0.6 & $3.9 \times 10^{16}$ & 26 \\
\hline $\mathrm{HCO}$ & $4.3 \times 10^{14}$ & 0.16 & $3.4 \times 10^{15}$ & 2.3 \\
\hline GA & $1.7 \times 10^{15}$ & 0.6 & $6.5 \times 10^{15}$ & 4.3 \\
\hline EG & $<1 \times 10^{15}$ & $<0.4$ & $7 \times 10^{15}$ & 4.7 \\
\hline $\mathrm{CH}_{3} \mathrm{OH}$ & $2 \times 10^{16}$ & 8 & $2.9 \times 10^{16}$ & 19 \\
\hline POM & $1.9 \times 10^{17 a}$ & 72 & n.d & n.d \\
\hline $\mathrm{HCOOH}$ & n.d & n.d. & $<1 \times 10^{15}$ & $<1$ \\
\hline $\mathrm{H}_{2} \mathrm{CO}_{3}$ & n.d. & n.d & $1 \times 10^{14}$ & $<0.1$ \\
\hline
\end{tabular}

Notes. The time of photolysis is $3 \mathrm{~h}$ in the case of pure $\mathrm{H}_{2} \mathrm{CO}$ and $23 \mathrm{~h}$ in the case of the $\mathrm{H}_{2} \mathrm{O}: \mathrm{H}_{2} \mathrm{CO}$ ice mixture. The total amount of $\mathrm{H}_{2} \mathrm{CO}$ consumed $\left(\mathrm{N}_{\mathrm{c}}\left(\mathrm{H}_{2} \mathrm{CO}\right)\right)$ is $2.7 \times 10^{17}$ molec cm $\mathrm{cm}^{-2}$ for pure $\mathrm{H}_{2} \mathrm{CO}$ and $1.5 \times 10^{17}$ for the $\mathrm{H}_{2} \mathrm{O}: \mathrm{H}_{2} \mathrm{CO}$ ice mixture. The yields have been calculated as follows: $(\%)=N(\mathrm{X}) / N_{\mathrm{c}}\left(\mathrm{H}_{2} \mathrm{CO}\right) .{ }^{(a)}$ This value has been calculated as follow $N(\mathrm{POM})=N_{\mathrm{c}}\left(\mathrm{H}_{2} \mathrm{CO}\right)-\Sigma N(\mathrm{X})$.

its thermal decomposition into formaldehyde (Duvernay et al. 2014; Hiraoka et al. 2005; Le Roy et al. 2012).

The assignment of the products observed in the solid film has been also confirmed by mass spectrometry. The newly formed species are monitored in situ by a temperature programmed desorption (TPD) using a quadrupole mass spectrometer (QMS) to analyse thermally desorbed species during the warming. Figure 3 presents typical QMS TPD spectra of the solid film obtained after sublimation of the photolysed $\mathrm{H}_{2} \mathrm{CO}$. It is clear that in the temperature range $100-300 \mathrm{~K}$, desorption peaks appear at 150, 195, 205, 220, and $235 \mathrm{~K}$ corresponding to the five products. TPD QMS spectra provide information to identify the origin of the carriers. Indeed, molecules desorb at specific temperatures and fragmentation patterns upon electron impact induced dissociative ionisation characteristic of a molecular structure (Fig. 3 and Table 4). Two products can be
Table 4. Desorption temperature and characteristic peaks of fragmentation $(\mathrm{m} / \mathrm{z})$ of pure $\mathrm{H}_{2} \mathrm{CO}, \mathrm{CH}_{3} \mathrm{OH}, \mathrm{HCOOH}, \mathrm{GA}, \mathrm{EG}$, and POM.

\begin{tabular}{|c|c|c|c|}
\hline Molecules & $\begin{array}{c}\text { Desorption } \\
\text { temperature }(\mathrm{K})\end{array}$ & $\begin{array}{l}m / z \\
(\%)\end{array}$ & Attribution \\
\hline $\mathrm{H}_{2} \mathrm{CO}$ & $100-110 \mathrm{~K}$ & $\begin{array}{l}30(60) \\
29(100)\end{array}$ & $\begin{array}{c}\mathrm{CH}_{2} \mathrm{O}^{+} \\
\mathrm{HCO}^{+}\end{array}$ \\
\hline $\mathrm{CH}_{3} \mathrm{OH}$ & $140-150 \mathrm{~K}$ & $\begin{array}{l}32(75) \\
31(100) \\
30(7) \\
29(50)\end{array}$ & $\begin{array}{c}\mathrm{CH}_{3} \mathrm{OH}^{+\cdot} \\
\mathrm{HOCH}_{2}^{+} \\
\mathrm{HCH}_{2} \mathrm{O}^{+} \\
\mathrm{HCO}^{+}\end{array}$ \\
\hline $\mathrm{HCOOH}$ & $170-180 \mathrm{~K}$ & $\begin{array}{l}46(80) \\
45(29) \\
29(100)\end{array}$ & $\begin{array}{c}\mathrm{HCOOH}^{+} \\
\mathrm{HCOO}^{+} \\
\mathrm{HCO}^{+}\end{array}$ \\
\hline GA & $170-180 \mathrm{~K}$ & $\begin{array}{l}60(10) \\
32(50) \\
31(100) \\
30(7) \\
29(40)\end{array}$ & $\begin{array}{c}\mathrm{HCOCH}_{2} \mathrm{OH}^{+\cdot} \\
\mathrm{O}_{2}^{+\cdot} \\
\mathrm{H}_{2} \mathrm{COH}^{+} \\
\mathrm{HCH}_{2} \mathrm{O}^{+\cdot} \\
\mathrm{HCO}^{+}\end{array}$ \\
\hline EG & $220-230 \mathrm{~K}$ & $\begin{array}{l}62(10) \\
61(7) \\
43(16) \\
33(36) \\
32(10) \\
31(100) \\
30(5) \\
29(20)\end{array}$ & $\begin{array}{c}\mathrm{HOCH}_{2} \mathrm{CH}_{2} \mathrm{OH}^{+\cdot} \\
\mathrm{OCH}_{2} \mathrm{CH}_{2} \mathrm{OH}^{+} \\
\mathrm{C}_{2} \mathrm{H}_{3} \mathrm{O}^{+} \\
\mathrm{OOH}^{+} \\
\mathrm{H}_{3} \mathrm{COH}^{+} \\
\mathrm{H}_{2} \mathrm{COH}^{+} \\
\mathrm{CH}_{2} \mathrm{O}^{+\cdot} \\
\mathrm{HCO}^{+}\end{array}$ \\
\hline POM & $220-280 \mathrm{~K}$ & $\begin{array}{l}61(15) \\
47(5) \\
31(29) \\
30(70) \\
29(100)\end{array}$ & $\begin{array}{c}\mathrm{CH}_{2} \mathrm{OCH}_{2} \mathrm{OH}^{+} \\
\mathrm{OCH}_{2} \mathrm{OH}^{+} \\
\mathrm{HOCH}_{2}^{+} \\
\mathrm{CH}_{2} \mathrm{O}^{+\cdot} \\
\mathrm{HCO}^{+}\end{array}$ \\
\hline
\end{tabular}

Notes. Only peaks with intensities higher than $5 \%$ are listed.

easily identified by comparing desorption temperatures and the fragmentation patterns. Methanol is detected from the signal at $m / z 32\left(\mathrm{CH}_{3} \mathrm{OH}^{+\bullet}\right)$ observed at $150 \mathrm{~K}$ (Fedoseev et al. 2015; Maity et al. 2015; Butscher et al. 2015). The signal observed for the $m / z, 62\left(\mathrm{HOCH}_{2} \mathrm{CH}_{2} \mathrm{OH}^{+\bullet}\right)$ at $220 \mathrm{~K}$ is due to the desorption of EG (Fedoseev et al. 2015; Maity et al. 2015; Butscher et al. 2015). Around $200 \mathrm{~K}$ several characteristic ions are observed at $\mathrm{m} / \mathrm{z}$ 32, 47, 60, and 61 owing to the partial co-desorption of GA and POM (Table 4). More precisely, the desorption of GA is detected at $195 \mathrm{~K}$ from the $\mathrm{m} / \mathrm{z} 32$ and 60, while the POM desorption is observed at $205 \mathrm{~K}$ from its characteristic fragments $\mathrm{m} / \mathrm{z} 47$ and 61 (Duvernay et al. 2014; Hiraoka et al. 2005; Danger et al. 2014). The last compound that shows up at $234 \mathrm{~K}$ is characterised by two ions at $\mathrm{m} / \mathrm{z} 47$ and 61 that could also be due to POM desorption (Table 4). However, the intensity ratio between $\mathrm{m} / \mathrm{z} 47$ and 61 is different from the previous POM desorption at $205 \mathrm{~K}$ suggesting that the POM structure is different.

\subsection{VUV photolysis of $\mathrm{H}_{2} \mathrm{CO}$ in water-dominated ice}

Figure 4 shows the mid-IR spectra of an $\mathrm{H}_{2} \mathrm{O}: \mathrm{H}_{2} \mathrm{CO}=5$ ice mixture at $13 \mathrm{~K}$ before and after $23 \mathrm{~h}$ of VUV photolysis at 


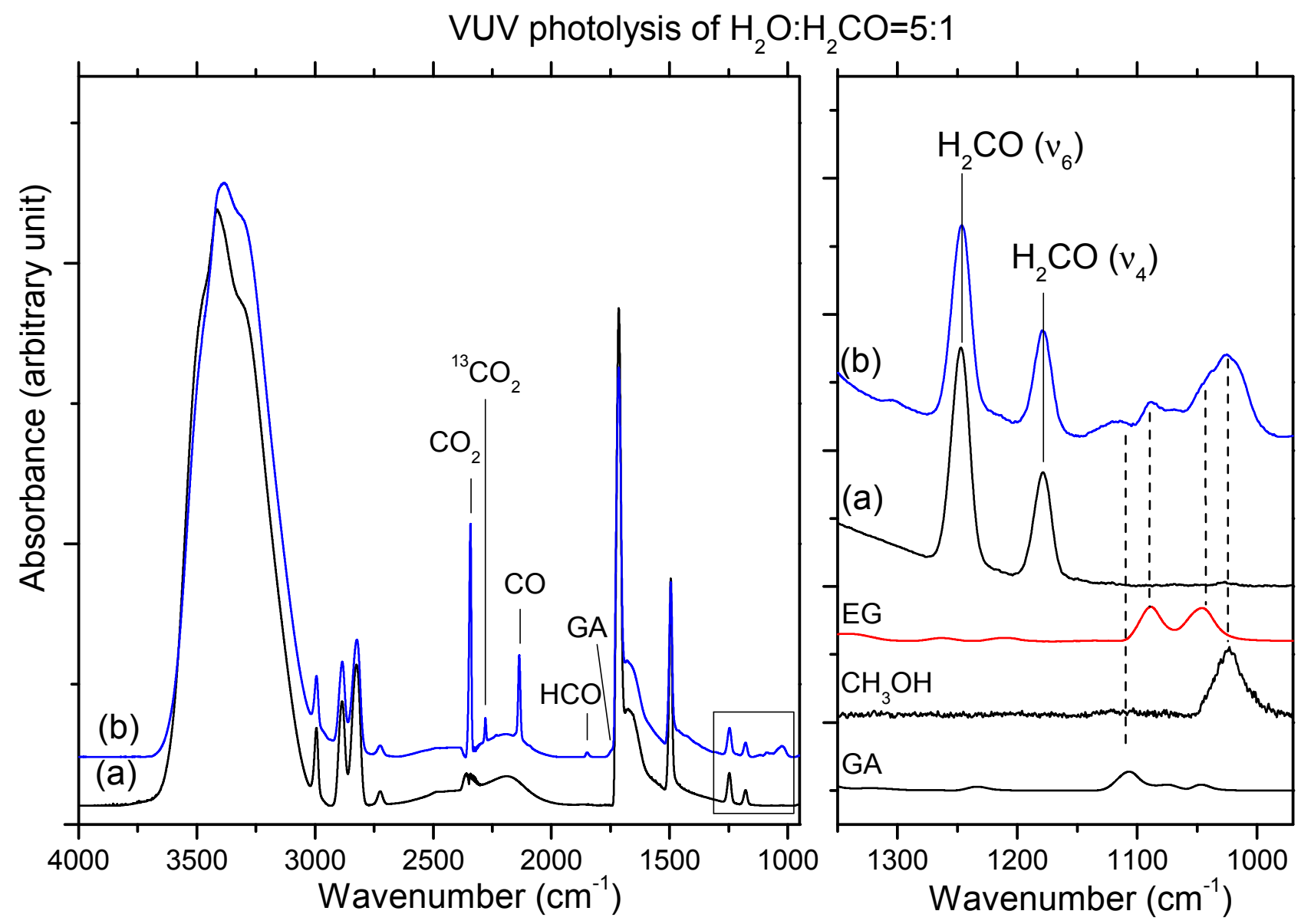

Fig. 4. Left panel: infrared spectra of $\mathrm{H}_{2} \mathrm{CO}$ in water-dominated ice deposited at $13 \mathrm{~K}$ (a) and after $23 \mathrm{~h}$ of VUV photolysis (b) at $13 \mathrm{~K}$. Right panel: the $v(\mathrm{C}-\mathrm{O})$ stretching region has been enlarged for clarity. The infrared spectra recorded before and after photolysis at $13 \mathrm{~K}$ of $\mathrm{H}_{2} \mathrm{CO}$ in water-dominated ice are compared with reference spectra recorded at $13 \mathrm{~K}$ of pure ethylene glycol (EG), methanol, and glycolaldehyde (GA).

Lyman- $\alpha$. The infrared bands of $\mathrm{H}_{2}^{12} \mathrm{CO}$ and $\mathrm{H}_{2}^{13} \mathrm{CO}$ in waterdominated ice are given in Table 1. Comparing the spectrum of the unirradiated ice with that recorded after irradiation shows that formaldehyde bands are reduced by about $30 \%$. Its time decay is fitted with a first-order kinetic rate. The corresponding kinetic constant is found to be $1.94 \times 10^{-5} \mathrm{~s}^{-1}$. With our photon fluence the corresponding photodissociation cross-section can be estimated to be $\sigma_{\text {photo }}=7.8 \times 10^{-19} \mathrm{~cm}^{-2}$ which is ten times lower than the value measured in the case of pure formaldehyde. New features grow at 2342,2138, and $1860 \mathrm{~cm}^{-1}$ (Table 5) that can be readily assigned to $\mathrm{CO}_{2}, \mathrm{CO}$, and $\mathrm{HCO}$, respectively (Gerakines et al. 1996; Milligan \& Jacox 1969). In addition to these three products already observed in the case of the photolysis of pure formaldehyde, a broad feature is also detected in the $\mathrm{C}-\mathrm{O}$ stretching region around $1100 \mathrm{~cm}^{-1}$ (Fig. 4). This region has been enlarged in the right panel of Fig. 4 for clarity. The characteristic band of methanol is clearly observed at $1025 \mathrm{~cm}^{-1}$. Gylcolaldehyde is also detected through its bands located at 1748 and $1120 \mathrm{~cm}^{-1}$ (Hudson et al. 2005). Finally, the bands at 1089 and 1040 (shoulder) $\mathrm{cm}^{-1}$ can be assigned to ethylene glycol (Hudson et al. 2005). Reference spectra of these three compounds are given in Fig. 4 for direct comparison with infrared spectrum recorded at $13 \mathrm{~K}$ after photolysis. Unlike the case of pure formaldehyde, no POM is observed after photolysis. This is due to the dilution of formaldehyde in water ice which slows down polymerisation reactions since species diffusion is highly inhibited at $13 \mathrm{~K}$ (Mispelaer et al. 2013). The final abundances are listed in Table 3. The dominant product is the carbon monoxide (40\%). However, $\mathrm{CO}_{2}$ relative abundance is dramatically increased in water-dominated ices (Table 3 ). The reactivity of $\mathrm{OH}$ radicals - formed by the water photolysis - with $\mathrm{CO}$ explains this phenomena (Oba et al. 2010). H-atom addition during the photolysis is also at the origin of the higher amount of methanol (19\% instead of $8 \%$ in the case of pure formaldehyde). Finally GA and EG represent $4.3 \%$ and $4.7 \%$ of the photoproducts. After photolysis at $13 \mathrm{~K}$, the sample is gradually warmed at a rate of $4 \mathrm{~K} \mathrm{~min}^{-1}$. Between 50 and $70 \mathrm{~K}$ bands relative to the $\mathrm{HCO}$ radical and $\mathrm{H}_{2} \mathrm{CO}$ decrease, while those of GA (1748 and $\left.1120 \mathrm{~cm}^{-1}\right)$ and EG increase $\left(1089\right.$ and $\left.1040 \mathrm{~cm}^{-1}\right)$ as does a band at $1012 \mathrm{~cm}^{-1}$ (Fig. 5). This indicates that a thermally induced radical chemistry occurs during the warming due to the increase of species mobility within the ice bulk which enhances the radical-radical encounter probability.

After water ice desorption (between 170 and $190 \mathrm{~K}$ ) that releases a large fraction of the photo-products, a refractory compound that fully sublimates after $230 \mathrm{~K}$ remains on the sample holder. Its infrared spectrum recorded at $200 \mathrm{~K}$ is shown in Fig. 6 (left panel). This species is characterised by a strong $\mathrm{OH}$ stretching mode at $3236 \mathrm{~cm}^{-1}$, a C-H stretching mode at $2915 \mathrm{~cm}^{-1}$, a $\mathrm{C}=\mathrm{O}$ stretching mode at $1726 \mathrm{~cm}^{-1}$, and a $\mathrm{C}-\mathrm{O}$ stretching mode at $1018 \mathrm{~cm}^{-1}$. Based on the infrared analysis, this species is tentatively assigned to an oligomer of formaldehyde (i.e. short chain POM) initiated by HCO radical. This is consistent with the consumption of both formaldehyde and HCO during the warming 


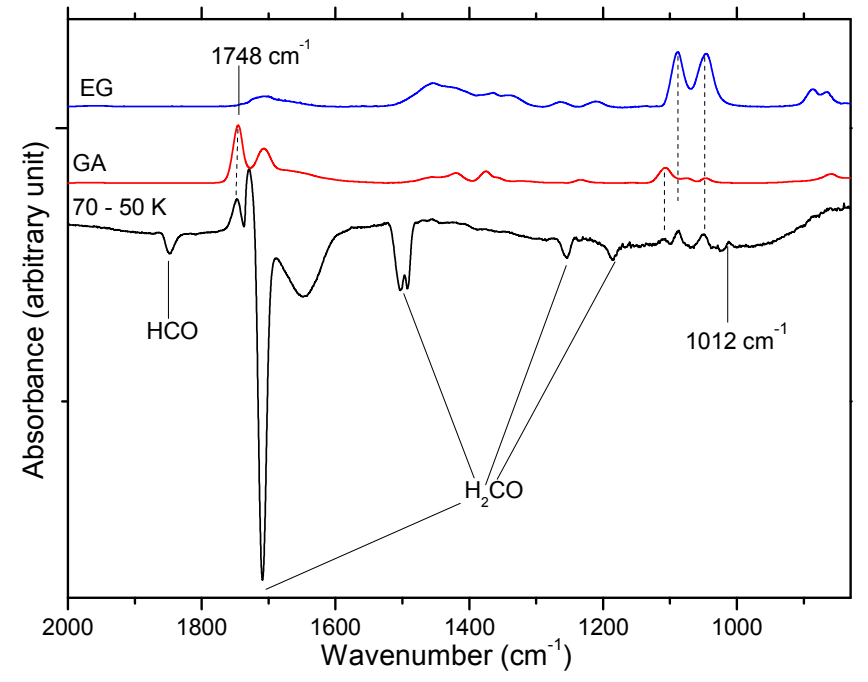

Fig. 5. Infrared difference spectrum showing the effect of warming the photolysed $\mathrm{H}_{2} \mathrm{O}: \mathrm{H}_{2} \mathrm{CO}$ ice. Negative bands are related to species that are consumed during the warming, while positive bands are related to species that are formed during the warming. This difference spectrum is compared with pure GA and EG.

Table 5. New bands observed during the VUV photolysis of $\mathrm{H}_{2} \mathrm{O}: \mathrm{H}_{2} \mathrm{CO}=5: 1$ ice at $13 \mathrm{~K}$.

\begin{tabular}{|c|c|c|c|c|c|}
\hline \multicolumn{2}{|c|}{$v\left(\mathrm{~cm}^{-1}\right)$} & \multirow[t]{2}{*}{ Mode } & \multirow{2}{*}{$\begin{array}{c}A \\
\left(\mathrm{~cm} \mathrm{molec}^{-1}\right)\end{array}$} & \multirow[t]{2}{*}{ Molecule } & \multirow[t]{2}{*}{ Ref. } \\
\hline${ }^{12} \mathrm{C}$ & ${ }^{13} \mathrm{C}$ & & & & \\
\hline 2342 & 2276 & $v(\mathrm{CO})$ & $7.1 \times 10^{-17}$ & $\mathrm{CO}_{2}$ & $a$ \\
\hline 2138 & 2089 & $v(\mathrm{CO})$ & $1.7 \times 10^{-17}$ & $\mathrm{CO}$ & $b$ \\
\hline 1860 & 1809 & $v(\mathrm{C}=\mathrm{O})$ & $2.1 \times 10^{-17}$ & $\mathrm{HCO}$ & $c$ \\
\hline 1748 & 1693 & $v(\mathrm{C}=\mathrm{O})$ & $2.6 \times 10^{-17}$ & GA & $d$ \\
\hline 1120 & & $v(\mathrm{C}-\mathrm{O})$ & $8.1 \times 10^{-18}$ & GA & $d$ \\
\hline 1089 & 1063 & $v(\mathrm{C}-\mathrm{O})$ & $3.9 \times 10^{-18}$ & EG & $d$ \\
\hline 1040 & 1029 & $v(\mathrm{C}-\mathrm{O})$ & $3.9 \times 10^{-18}$ & EG & $d$ \\
\hline 1025 & 1003 & $v(\mathrm{C}-\mathrm{O})$ & $1.5 \times 10^{-17}$ & $\mathrm{CH}_{3} \mathrm{OH}$ & $e$ \\
\hline
\end{tabular}

Notes. $v$ : stretching; $\delta$ : bending; $\rho$ : rocking; $\omega$ : wagging. ${ }^{(a)}$ Gerakines et al. (1996); ${ }^{(b)}$ Hudson \& Moore (1999); ${ }^{(c)}$ Bennett \& Kaiser (2007); ${ }^{(d)}$ Hudson et al. (2005); ${ }^{(e)}$ Hudgins et al. (1993); ${ }^{(f)}$ Gerakines et al. (2000).

and the increase of the infrared absorption at $1012 \mathrm{~cm}^{-1}$ (Fig. 5). The slight frequency shift $\left(-6 \mathrm{~cm}^{-1}\right)$ observed for this band is due to changes in the environment. This mode is observed at $1012 \mathrm{~cm}^{-1}$ in water ice (i.e. before the water ice sublimation) and at $1018 \mathrm{~cm}^{-1}$ in the solid film after the water ice sublimation.

During the warming, the sublimation of formaldehyde and photoproducts starts after $100 \mathrm{~K}$ and is investigated by mass spectroscopy (Fig. 7). As previously, TPD spectra recorded during the warm-up will give access to additional information about the identification of species formed after photolysis at $13 \mathrm{~K}$. In Fig. 7, the TPD spectra are presented for a range of temperatures from $120 \mathrm{~K}$ to $270 \mathrm{~K}$ recorded after $23 \mathrm{~h}$ of VUV photolysis of $\mathrm{H}_{2} \mathrm{O}: \mathrm{H}_{2} \mathrm{CO}=5: 1$ at $13 \mathrm{~K}$. Seven sublimation peaks are detected, labelled from (a) to (g) in Fig. 7. The first sublimation peak centred at $155 \mathrm{~K}$ (labelled (a) in Fig. 7) is due to the molecular ion of methanol $\mathrm{m} / z 32 \mathrm{CH}_{3} \mathrm{OH}^{+\bullet}$ (Table 4). The TPD spectra are more complicated between $170 \mathrm{~K}$ and $190 \mathrm{~K}$ where three desorption peaks are observed (labelled from (b)

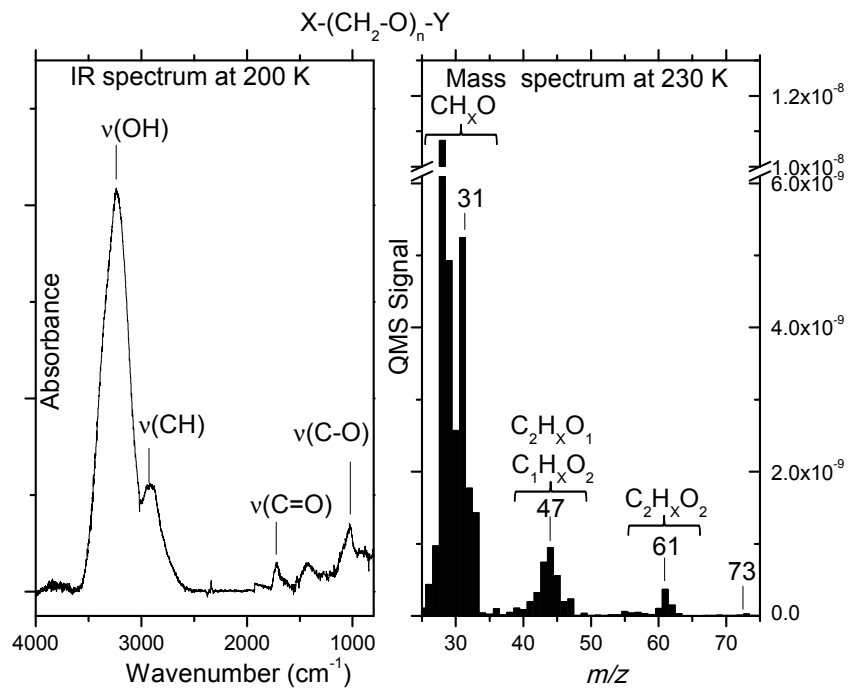

Fig. 6. Left panel: infrared spectrum of the oligomer of formaldehyde $\left(\mathrm{X}-\left(\mathrm{CH}_{2}-\mathrm{O}\right)_{n}-\mathrm{Y}\right)$ obtained at $200 \mathrm{~K}$ after $23 \mathrm{~h}$ of VUV photolysis of an $\mathrm{H}_{2} \mathrm{O}: \mathrm{H}_{2} \mathrm{CO}$ ice mixture 5:1 at $13 \mathrm{~K}$. Right panel: corresponding mass spectrum recorded at $230 \mathrm{~K}$.

to (d) in Fig. 7). The previous observations are an indication of co-sublimation during water-ice desorption that may trigger the sublimation of the other products (Maity et al. 2015; Noble et al. 2012). These co-desorption peaks can be assigned to four products. Formic acid is detected from its characteristic ion at $m / z 46$ assigned to $\mathrm{HCOOH}^{+\bullet}$ (Table 4). Carbonic acid $\left(\mathrm{H}_{2} \mathrm{CO}_{3}\right)$ in turn is detected thanks to $\mathrm{m} / z, 61$ attributed to $\mathrm{HCO}_{3}^{+}$. Detection of these two species are not surprising since they have already been observed in the VUV photolysis of $\mathrm{H}_{2} \mathrm{O}: \mathrm{CO}_{2}$ ice mixture (Gerakines et al. 2000). However, they were not observed during the infrared analysis owing to the lower sensibility of this technique. Co-desorption of GA and EG during the water ice desorption is suspected between $170 \mathrm{~K}$ and $190 \mathrm{~K}$ since small signals at $\mathrm{m} / \mathrm{z} 32,60$, and 62 are also observed (Table 4). This is more pronounced at $200 \mathrm{~K}$ and $212 \mathrm{~K}$ where remaining GA and EG desorb, as seen in Fig. 7 (labelled (e) and (f) respectively). Finally, desorption of the refractory species previously assigned to an oligomer of formaldehyde $\left(\mathrm{X}-\left(\mathrm{CH}_{2}-\mathrm{O}\right)_{n}-\mathrm{Y}\right)$ is observed around $230 \mathrm{~K}$ (labelled $(\mathrm{g})$ in Fig. 7), which is consistent with the infrared analysis (Duvernay et al. 2014). The mass spectrum of this species recorded at $230 \mathrm{~K}$ is shown in the right panel of Fig. 6. This spectrum is dominated by several ions at $m / z 31,47,61$, and 73 corresponding to $\mathrm{CH}_{2} \mathrm{OH}^{+}, \mathrm{OCH}_{2} \mathrm{OH}^{+}, \mathrm{CH}_{2} \mathrm{OCH}_{2} \mathrm{OH}^{+}$, and $\mathrm{HCOCH}_{2} \mathrm{OCH}_{2}^{+}$. This fragmentation pattern is consistent with a structure such as $\mathrm{HCOCH}_{2} \mathrm{OCH}_{2} \mathrm{OH}(M=90 \mathrm{u})$, and also with the infrared analysis.

\section{Discussion}

\subsection{Chemical network}

As described by Butscher et al. (2015), Fedoseev et al. (2015), and Chuang et al. (2016), the COM formation observed in the water-free experiment can be explained by the interaction of intermediate radicals that are formed upon VUV photolysis of $\mathrm{H}_{2} \mathrm{CO}$. The dominant observed radical is $\mathrm{HCO}$, which is formed from the $\mathrm{C}-\mathrm{H}$ homolytic bond cleavage of $\mathrm{H}_{2} \mathrm{CO}$ triggered by VUV photons:

$\mathrm{H}_{2} \mathrm{CO}+h v \rightarrow \mathrm{HCO}+\mathrm{H}$. 
T. Butscher et al.: Radical-induced chemistry from VUV photolysis of interstellar ice analogues containing formaldehyde

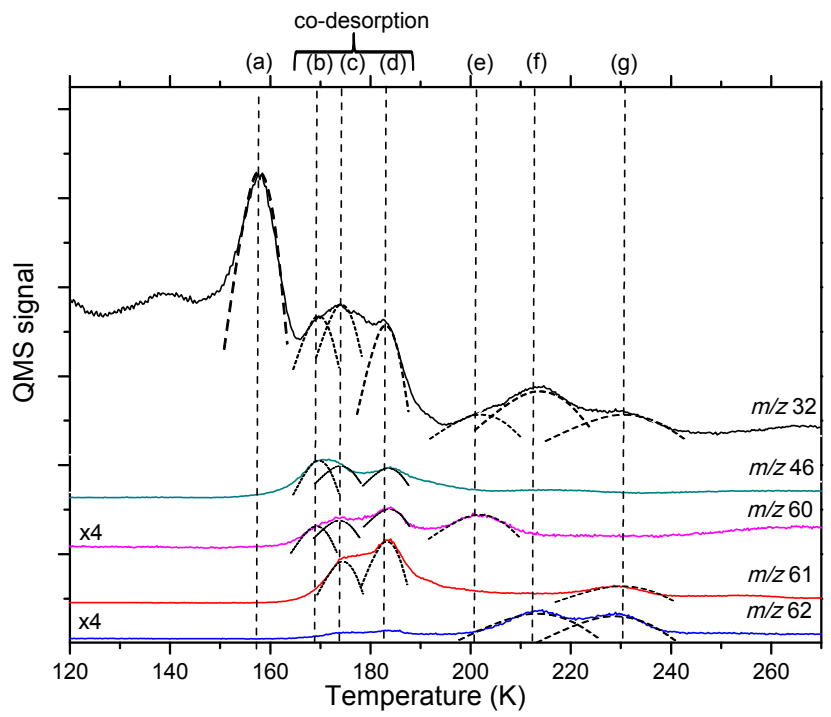

Fig. 7. TPD spectra $\left(4 \mathrm{~K} \mathrm{~min}^{-1}\right)$ obtained after VUV photolysis of an ice mixture containing $\mathrm{H}_{2} \mathrm{O}: \mathrm{H}_{2} \mathrm{CO}=5: 1$. The photolysis is performed at $13 \mathrm{~K}$ for $23 \mathrm{~h}$. Only the relevant $\mathrm{m} / \mathrm{z}$ values are shown. Detected species are indicated by the letters a-g at their desorption temperature: (a) $\mathrm{CH}_{3} \mathrm{OH}(\mathrm{m} / z$ 32); (b), (c), (d partial co-desorption between $\mathrm{HCOOH}$ $\left(\mathrm{m} / \mathrm{z}\right.$ 46), $\mathrm{H}_{2} \mathrm{CO}_{3}(\mathrm{~m} / \mathrm{z} 61)$, GA $(\mathrm{m} / \mathrm{z} 60)$, and $\mathrm{EG}(\mathrm{m} / \mathrm{z}, 62)$ during water desorption; (e) GA $(m / z$ 60); (f) EG $(m / z 62)$; (g) oligomer of formaldehyde $\mathrm{X}-\left(\mathrm{CH}_{2}-\mathrm{O}\right)_{n}-\mathrm{Y}$ with $n<5$

Alternatively, $\mathrm{HCO}$ can be formed from $\mathrm{H}$-atom addition on formaldehyde (Hiraoka et al. 2005; Minissale et al. 2016):

$\mathrm{H}_{2} \mathrm{CO}+\mathrm{H} \rightarrow \mathrm{HCO}+\mathrm{H}_{2}$.

The carbon dioxide observed in the water-free experiment can be explained by the following reaction (Loeffler et al. 2005):

$\mathrm{CO}+h v \rightarrow \mathrm{CO}^{*} \stackrel{\mathrm{CO}}{\longrightarrow} \mathrm{CO}_{2}+\mathrm{C}$.

Radical-induced polymerisation is a well-known mechanism and has been already reported at low temperature $(T<10 \mathrm{~K})$ in the case of $\mathrm{H}_{2} \mathrm{CO}$ (Gerakines et al. 1996; Hiraoka et al. 2005). In a pure $\mathrm{H}_{2} \mathrm{CO}$ film, the $\mathrm{HCO}$ radical (initiator radical) reacts with the formaldehyde initiating a polymerisation reaction:

$\mathrm{HCO}+\mathrm{H}_{2} \mathrm{CO} \rightarrow \mathrm{CHO}-\mathrm{CH}_{2}-\mathrm{O}$ (initiation).

The newly created radical (activated monomer) can further react on another formaldehyde molecule and so on, increasing the chain length through propagation steps:

$\mathrm{CHO}-\mathrm{CH}_{2}-\mathrm{O}+\mathrm{n} \mathrm{H}_{2} \mathrm{CO} \rightarrow \mathrm{CHO}-\left(\mathrm{CH}_{2}-\mathrm{O}\right)_{n+1}$ (propagation).

Chain termination (term) can occur by different mechanisms:

$\mathrm{CHO}-\left(\mathrm{CH}_{2}-\mathrm{O}\right)_{n+1}+\mathrm{H} \rightarrow \mathrm{CHO}-\left(\mathrm{CH}_{2}-\mathrm{O}\right)_{\mathrm{n}+1}-\mathrm{H}($ term $)$,

$\mathrm{CHO}-\left(\mathrm{CH}_{2}-\mathrm{O}\right)_{n+1}+\mathrm{HCO} \rightarrow \mathrm{CHO}-\left(\mathrm{CH}_{2}-\mathrm{O}\right)_{\mathrm{n}+1}-\mathrm{CHO}$ (term).

Additions of $\mathrm{H}$-atoms on formaldehyde lead to a key radical $\mathrm{CH}_{2} \mathrm{OH}$ (Butscher et al. 2015; Woods et al. 2012, 2013) and methanol (Watanabe \& Kouchi 2002):

$\mathrm{H}_{2} \mathrm{CO}+\mathrm{H} \rightarrow \mathrm{CH}_{2} \mathrm{OH}$,

$\mathrm{CH}_{2} \mathrm{OH}+\mathrm{H} \rightarrow \mathrm{CH}_{3} \mathrm{OH}$.
The $\mathrm{CH}_{2} \mathrm{OH}$ radical can react on the $\mathrm{HCO}$ radical via a barrierless reaction forming GA (Butscher et al. 2015),

$\mathrm{CH}_{2} \mathrm{OH}+\mathrm{HCO} \rightarrow \mathrm{CHOCH}_{2} \mathrm{OH}(\mathrm{GA})$,

and EG can be formed from the dimerisation of the $\mathrm{CH}_{2} \mathrm{OH}$ radical (Butscher et al. 2015):

$\mathrm{CH}_{2} \mathrm{OH}+\mathrm{CH}_{2} \mathrm{OH} \rightarrow \mathrm{HOCH}_{2} \mathrm{CH}_{2} \mathrm{OH}(\mathrm{EG})$.

We also performed the formaldehyde photolysis in waterdominated ices. Several differences were observed that can be explained by the VUV photolysis of water during the experiments which produces a large number of $\mathrm{H}$-atoms and $\mathrm{HO}$ radicals (Yabushita et al. 2008; Gerakines et al. 1996):

$\mathrm{H}_{2} \mathrm{O}+h v \rightarrow \mathrm{HO}+\mathrm{H}$.

Thus, the $\mathrm{HO}$ reactivity and $\mathrm{H}$-atom additions should therefore be considered and can account for most of the differences observed in water-free and water dominated experiments. The carbon dioxide observed in water-dominated ice experiments can be formed by reaction (5) as in the pure solid, but also by the $\mathrm{HO}$ radical reactivity on $\mathrm{CO}$ (reaction (15)). This may explain the larger amount of $\mathrm{CO}_{2}$ in the water-dominated ices compared with photolysis in water-free ices (Table 3 ):

$\mathrm{CO}+\mathrm{OH} \rightarrow \mathrm{CO}_{2}+\mathrm{H}$.

The dominating pathway to formic acid ( $\mathrm{HCOOH})$ was found to involve the addition of suprathermal hydrogen atoms to carbon monoxide forming the formyl radical (HCO); this radical recombines with neighbouring hydroxyl radicals to yield formic acid $(\mathrm{HCOOH})$. To a lesser extent, hydroxyl radicals react with carbon monoxide to yield the hydroxyformyl radical (HOCO), which recombines with atomic hydrogen to produce formic acid (Bennett et al. 2010):

$\mathrm{HCO}+\mathrm{OH} \rightarrow \mathrm{HCOOH}$

$\mathrm{HO}+\mathrm{CO} \rightarrow \mathrm{HOCO} \stackrel{\mathrm{H}}{\longrightarrow} \mathrm{HCOOH}$

$\mathrm{HO}$ radical reactivity on $\mathrm{CO}_{2}$ produces carbonic acid $\left(\mathrm{H}_{2} \mathrm{CO}_{3}\right)$ :

$\mathrm{HO}+\mathrm{CO}_{2} \rightarrow \mathrm{HOCO}_{2} \stackrel{\mathrm{H}}{\longrightarrow} \mathrm{H}_{2} \mathrm{CO}_{3}$.

Formaldehyde and HO radical reactivity should also be considered and may explain the formation of the formaldehyde oligomer (i.e. short chain POMs) during the warming of the photolysed water-dominated ice:

$\mathrm{HO}+\mathrm{H}_{2} \mathrm{CO} \rightarrow \mathrm{HOCH}_{2} \mathrm{O} \stackrel{\mathrm{H}_{2} \mathrm{CO}}{\longrightarrow} \mathrm{HOCH}_{2} \mathrm{OCH}_{2} \mathrm{O}$.

Termination reactions (such as reactions (8) and (9)) with other free radicals $(\mathrm{H}, \mathrm{HO}, \mathrm{HCO}$, etc.) produce the formaldehyde oligomer $\left(\mathrm{X}-\left(\mathrm{CH}_{2}-\mathrm{O}\right)_{n}-\mathrm{Y}\right.$ with $\left.n<5\right)$ (Duvernay et al. 2014).

A striking difference between the water-free and waterdominated experiments concerns the variation of photodissociation rates. It is 10 times higher in water-free experiments than in water-dominated experiments. Several reasons can be given to explain this difference. First, as mentioned before, in water-dominated ice $\mathrm{H}_{2} \mathrm{O}$ molecules will absorb a large part of the VUV flux forming $\mathrm{H}$-atom and $\mathrm{HO}$ radicals $\left(\sigma_{\text {photo }}=\right.$ $2 \times 10^{-18} \mathrm{~cm}^{-2}$; Yabushita et al. 2008; Gerakines et al. 1996; Okabe et al. 1978). This in turn will lead to a decrease in the photodissociation rate of formaldehyde. On the other hand, it should 
be kept in mind that photodissociation cross-sections are global values that include not only absorption and dissociation, but also radical recombinations, polymerisation reactions, diffusion processes, etc. Second, in a pure solid, only trace of HCO radical formed from $\mathrm{H}_{2} \mathrm{CO}$ photolysis - can consume a large amount of $\mathrm{H}_{2} \mathrm{CO}$ by polymerisation reaction, whereas in water-dominated ice this reaction is slowed down by the dilution. Indeed, at low temperatures the mobility of molecules and radical species is highly inhibited and only radicals formed next to formaldehyde can react leading to a lower photodissociation cross-section in water ices than in the pure solid. In other words, we cannot disentangle consummation of formaldehyde induced by photodissociation or by polymerisation.

Another mechanism that may be important in waterdominated ice to explain the observed product after photolysis at $13 \mathrm{~K}$ is the local diffusion of newly formed radicals triggered by VUV photons. Radicals produced from photodissociation at Lyman- $\alpha(10.2 \mathrm{ev})$ in the ice may have an excess of translational energy and thus locally diffuse through the ice bulk even at $13 \mathrm{~K}$. It should be noted that this photon-assisted diffusion is only limited in time and space since the "hot" radical will be quickly thermalised in the ice bulk and thus stop moving. Photon-assisted diffusion may explain the GA formation at $13 \mathrm{~K}$ in water-dominated ices where thermal diffusion is very limited. The hot HCO radical formed after formaldehyde photolysis may diffuse enough to encounter another formaldehyde molecule and then react forming a $\mathrm{HCOCH}_{2} \mathrm{O}$ radical. A $\mathrm{H}$-atom addition on the later radical forms GA. In this mechanism, GA can be seen as the smaller POM initiated by the $\mathrm{HCO}$ radical with only one formaldehyde monomer $\mathrm{HCO}\left(\mathrm{CH}_{2} \mathrm{O}\right)_{1} \mathrm{H}$,

$$
\mathrm{HCO}+\mathrm{H}_{2} \mathrm{CO} \rightarrow \mathrm{HCOCH}_{2} \mathrm{O} \stackrel{\mathrm{H}}{\longrightarrow} \mathrm{CHOCH}_{2} \mathrm{OH}(\mathrm{GA}),
$$

and EG can also be formed from the reactivity of the $\mathrm{CH}_{2} \mathrm{OH}$ radical with formaldehyde followed by a $\mathrm{H}$-addition:

$$
\mathrm{CH}_{2} \mathrm{OH}+\mathrm{H}_{2} \mathrm{CO} \rightarrow \mathrm{HOCH}_{2} \mathrm{CH}_{2} \mathrm{O} \stackrel{\mathrm{H}}{\longrightarrow} \mathrm{HOCH}_{2} \mathrm{CH}_{2} \mathrm{OH}(\mathrm{EG}) .
$$

Interestingly, methylformate (an isomer of GA) is not observed in our experiment, whereas it is observed after methanol photolysis (Öberg et al. 2009) or when pure formaldehyde is intensively photolysed (more than 90\%) as observed by Gerakines et al. (1996). In the latter case, secondary photodissociation of methanol - one of the main photo-products of formaldehyde - also explains the formation of methylformate. In our experiments, the low VUV flux of our source prevents secondary photodissociation processes (such as methanol photolysis) from occurring, unlike the experiments performed by Gerakines et al. (1996). For comparison, the UV dose received by the sample in the Gerakines et al. (1996) experiments is ten times higher than in our experiments.

\subsection{Astrophysical significance}

The present experiments demonstrate that complex organic molecules are formed in formaldehyde and mixed water-formaldehyde ices exposed at $13 \mathrm{~K}$ to VUV photons. Solid state formaldehyde has long been identified as a key constituent within the interstellar/cometary grains in addition to ubiquitous water along with minor amounts of methane, ammonia, and carbon dioxide. The molecular abundance of formaldehyde within the icy mantles varies from $1 \%$ to $6 \%$ relative to water in several high- and low-mass protostars (Dartois 2005; Boogert et al. 2008) or hot corinos (Maret et al. 2004). These icy mantles are constantly being bombarded with high-energy galactic cosmic rays and/or exposed to the interstellar UV field. Consequently, chemical modifications of induced UV radiation on formaldehyde in water-dominated ices remains extremely important in understanding the chemical evolution of molecular clouds. Three COMs have been identified in our experiments: glycolaldehyde, ethylene glycol, and the formaldehyde polymer polyoxymethylene. Their formation pathways involve radical chemistry. In our case, the radicals are formed via photodissociation of formaldehyde triggered by VUV photons, which is likely to occur in star forming regions. Radical-radical recombinations are barrierless reactions, meaning that they may occur even at low temperatures. However in such cold environments the mobility is highly inhibited, which prevents recombination from occurring in water-dominated ices. At low temperatures when radicals are formed within the ice mantle from energetic processes or $\mathrm{H}$-addition, they will react only if they are next to each other. Otherwise, they are stored in the interstellar ices and "wait" for warmer environments such as star forming regions or cometary nuclei approaching the sun. In warmer environments, radicals will be able to move and thus be able to meet other reactive species such as radicals or unsaturated molecules and will form new compounds. Photo-assisted diffusion may also play a role in the formation of COMs in ice even at low temperature where radical diffusion is inhibited.

In our study, the photolysis of formaldehyde formed two key radicals, namely the formyl radical (HCO) and the hydroxymethyl radical $\left(\mathrm{CH}_{2} \mathrm{OH}\right)$, from photodissociation and $\mathrm{H}$-addition on formaldehyde, respectively. These radicals explain the formation of the observed products GA, EG, and POM at $13 \mathrm{~K}$ during photolysis and also during the warming, confirming the role of diffusion in radical-induced COM formation in water-dominated ices. This is consistent with the astronomical detection of GA and EG in star forming regions. First observed in Sagittarius B2 North Large Molecule Heimat (SB2NLMH; Hollis et al. 2000, 2001), glycolaldehyde has since been discovered in other systems, such as the hot molecular core G31.41+0.31 (Beltrán et al. 2009), the IRAS 16293-2422 protostar (Jørgensen et al. 2012), or more recently the NGC 1333IRAS2A protostar (Coutens et al. 2015). Ethylene glycol has been observed toward the protostars SB2N-LMH (Hollis et al. 2002) and NGC 1333-IRAS2A (Maury et al. 2014).

Surprisingly, the isomer of GA the methylformate (MF) is not detected in our experiments, while it is observed when methanol instead of formaldehyde is used as precursor (Öberg et al. 2009; Maity et al. 2015). These two isomers are both supposed to be formed from radical recombination involving $\mathrm{HCO}$ radical with $\mathrm{CH}_{2} \mathrm{OH}$ for $\mathrm{GA}$ formation and $\mathrm{CH}_{3} \mathrm{O}$ for $\mathrm{MF}$ formation. The molecular ratio between these two isomers is thus triggered by the $\mathrm{CH}_{2} \mathrm{O} / \mathrm{CH}_{3} \mathrm{O}$ ratio. In our experiments the $\mathrm{CH}_{2} \mathrm{OH}$ radical is essentially formed from $\mathrm{H}$-atom addition on formaldehyde (Butscher et al. 2015), and the non-detection of MF implies that $\mathrm{CH}_{3} \mathrm{O}$ is not efficiently formed from this process. However, the radical $\mathrm{CH}_{3} \mathrm{O}$ is likely to be formed via photodissociation of methanol (Öberg et al. 2009). This has important significance for astrochemistry. In dark molecular clouds, where hydrogenation reactions dominate, $\mathrm{H}$-additions on carbon monoxide should lead to the $\mathrm{HCO}$ radical, $\mathrm{H}_{2} \mathrm{CO}, \mathrm{CH}_{2} \mathrm{OH}$, and methanol, but not $\mathrm{CH}_{3} \mathrm{O}$. In such conditions, GA and EG formation should be favoured over MF formation. However, in star forming regions, grain surface reactions in ices rich in methanol triggered 
T. Butscher et al.: Radical-induced chemistry from VUV photolysis of interstellar ice analogues containing formaldehyde

by UV photons (Öberg et al. 2009) should form the HCO radical, $\mathrm{CH}_{2} \mathrm{OH}$ radical, and the $\mathrm{CH}_{3} \mathrm{O}$ radical thus forming $\mathrm{GA}, \mathrm{EG}$, and MF.

Complex organic molecules are also detected in comets that harbour the most pristine material in our solar system that may have preserved their interstellar heritage (Goesmann et al. 2015; Wright et al. 2015; Biver et al. 2014; Crovisier et al. 2004; Huebner 1987). The molecules GA, EG, and POM have been detected in comet 67P/Churyumov-Gerasimenko by COSAC and Ptolemy mass spectrometers on board the Rosetta lander Philae. Twenty-five minutes after Philae's initial comet touchdown, both instruments performed analyses that displayed 16 organic compounds including GA and EG (COSAC instrument), but also regular mass distributions suggesting the presence of a radiationinduced POM-like polymer (Ptolemy instrument; Wright et al. 2015). This confirms previous analysis with the PICCA instruments on comet Halley during the Giotto mission where a similar regular pattern of peaks was observed which was at that time tentatively assigned to POM-like structures (Huebner 1987). It should be kept in mind that currently polyoxymethylene is the best explanation for the distributed source of formaldehyde in cometary comae (Cottin \& Fray 2008). The presence of POM in comets is also supported by experimental results (Schutte et al. 1993). POM and POM-like polymers can be formed from the heating of interstellar/cometary ice analogues containing $\mathrm{H}_{2} \mathrm{CO}$, $\mathrm{NH}_{3}$, and $\mathrm{H}_{2} \mathrm{O}$ (Schutte et al. 1993; Danger et al. 2014; Noble et al. 2012; Vinogradoff et al. 2011). In this contribution we show an additional pathway for POM formation induced by radicals that might explain some observation made by the Ptolemy instrument on board Philae. The mass spectrum of the formaldehyde oligomer (see Fig. 6) recorded in this work shows masses at $m / z 29,31,47,61$, and 73 that have been also detected by the Ptolemy instruments (Wright et al. 2015). The authors of this study suggest that these masses come from radiation-induced POM-like polymer with an HCO termination as proposed by our analysis. This may indicate that POM-like polymers are readily formed in cometary grains by radical-induced polymerisation on formaldehyde initiated by the $\mathrm{HCO}$ radical as proposed in our study.

\section{Conclusion}

We report new laboratory experiments on the low-temperature solid state formation of complex organic molecules - glycolaldehyde, ethylene glycol, and polyoxymethylene - through radical-induced reactivity from VUV photolysis of formaldehyde in water-free and water-dominated ices. We show the ability of free radicals to be stored when formed at low temperatures in water-dominated ices and then to react with other radicals or on unsaturated molecules initiating polymerisation reactions when the temperature increases. It experimentally confirms the role of thermal diffusion in radical reactivity. We also showed that $\mathrm{H}$-atom additions to $\mathrm{H}_{2} \mathrm{CO}$ proceed preferentially through $\mathrm{CH}_{2} \mathrm{OH}$ intermediate radicals rather than through $\mathrm{CH}_{3} \mathrm{O}$ radicals. The reaction pathway proposed in this study for formaldehyde polymerisation in cometary grains induced by $\mathrm{HCO}$ radicals might explain the regular mass distributions detected by the Ptolemy instrument on board the Rosetta lander Philae.

Acknowledgements. This work was supported by the PCMI (Physique et Chimie du Milieu Interstellaire) programme and the CNES (Centre National d'Études spatiales).

\section{References}

Abou Mrad, N., Duvernay, F., Danger, G., \& Chiavassa, T. 2016, MNRAS accepted

Bacmann, A., García-García, E., \& Faure, A. 2016, A\&A, 588, L8

Beltrán, M. T., Codella, C., Viti, S., Neri, R., \& Cesaroni, R. 2009, ApJ, 690, L93

Bennett, C. J., \& Kaiser, R. I. 2007, ApJ, 661, 899

Bennett, C. J., Hama, T., Kim, Y. S., Kawasaki, M., \& Kaiser, R. I. 2010, ApJ, 727, 27

Biver, N., Bockelée-Morvan, D., Debout, V., et al. 2014, A\&A, 566, L5

Boogert, A., Pontoppidan, K., Knez, C., et al. 2008, ApJ, 678, 985

Bouilloud, M., Fray, N., Bénilan, Y., et al. 2015, MNRAS, 451, 2145

Butscher, T., Duvernay, F., Theule, P., et al. 2015, MNRAS, 453, 1587

Calcutt, H., Viti, S., Codella, C., et al. 2014, MNRAS, 443, 3157

Cernicharo, J., Marcelino, N., Roueff, E., et al. 2012, ApJ, 759, L43

Chuang, K.-J., Fedoseev, G., Ioppolo, S., van Dishoeck, E., \& Linnartz, H. 2016, MNRAS, 455, 1702

Cottin, H., \& Fray, N. 2008, Space Sci. Rev., 138, 179

Cottin, H., Moore, M. H., \& Bénilan, Y. 2003, ApJ, 590, 874

Coutens, A., Persson, M. V., Jørgensen, J. K., Wampfler, S. F., \& Lykke, J. M. 2015, A\&A, 576, A5

Crovisier, J., Bockelée-Morvan, D., Biver, N., et al. 2004, A\&A, 418, L35

Danger, G., Rimola, A., Mrad, N. A., et al. 2014, Phys. Chem. Chem. Phys., 16, 3360

Dartois, E. 2005, in ISO Science Legacy (Springer), 293

Duvernay, F., Danger, G., Theulé, P., Chiavassa, T., \& Rimola, A. 2014, ApJ, 791, 75

Fedoseev, G., Cuppen, H., Ioppolo, S., Lamberts, T., \& Linnartz, H. 2015, MNRAS, 448, 1288

Gerakines, P., Schutte, W., \& Ehrenfreund, P. 1996, A\&A, 312, 289

Gerakines, P., Moore, M., \& Hudson, R. 2000, A\&A, 357, 793

Gibb, E., Whittet, D., Schutte, W. a., et al. 2000, ApJ, 536, 347

Gibb, E., Whittet, D., Boogert, A., \& Tielens, A. 2004, ApJS, 151, 35

Goesmann, F., Rosenbauer, H., Bredehöft, J. H., et al. 2015, Science, 349 , aab0689

Henderson, B. L., \& Gudipati, M. S. 2015, ApJ, 800, 66

Herbst, E., \& Van Dishoeck, E. F. 2009, Ann. Rev. Astron. Astrophys., 47, 427

Hiraoka, K., Wada, A., Kitagawa, H., et al. 2005, ApJ, 620, 542

Hollis, J. M., Lovas, F. J., \& Jewell, P. R. 2000, ApJ, 540, L107

Hollis, J., Vogel, S., Snyder, L., Jewell, P., \& Lovas, F. 2001, ApJ, 554, L81

Hollis, J. M., Lovas, F. J., Jewell, P. R., \& Coudert, L. 2002, ApJ, 571, L59

Hudgins, D., Sandford, S., Allamandola, L., \& Tielens, A. 1993, ApJS, 86, 713

Hudson, R., \& Moore, M. 1999, Icarus, 140, 451

Hudson, R. L., \& Moore, M. H. 2000, Icarus, 145, 661

Hudson, R. L., Moore, M. H., \& Cook, A. M. 2005, Adv. Space Res., 36, 184

Huebner, W. 1987, Science, 237, 628

Jacox, M. E., \& Milligan, D. E. 1973, J. Mol. Spectrosc., 47, 148

Jørgensen, J. K., Favre, C., Bisschop, S. E., et al. 2012, ApJ, 757, L4

Kerkhof, O., Schutte, W., \& Ehrenfreund, P. 1999, A\&A, 346, 990

Le Roy, L., Briani, G., Briois, C., et al. 2012, Planet. Space Sci., 65, 83

Loeffler, M., Baratta, G., Palumbo, M., Strazzulla, G., \& Baragiola, R. 2005, A\&A, 435, 587

Maity, S., Kaiser, R. I., \& Jones, B. M. 2015, Phys. Chem. Chem. Phys., 17, 3081

Maret, S., Ceccarelli, C., Caux, E., et al. 2004, A\&A, 416, 577

Martín-Doménech, R., Caro, G. M., \& Cruz-Díaz, G. 2016, A\&A, 589, A107

Maury, A., Belloche, A., André, P., et al. 2014, A\&A, 563, L2

Milligan, D. E., \& Jacox, M. E. 1969, J. Chem. Phys., 51, 277

Minissale, M., Dulieu, F., Cazaux, S., \& Hocuk, S. 2016, A\&A, 585, A24

Mispelaer, F., Theulé, P., Aouididi, H., et al. 2013, A\&A, 555, A13

Noble, J., Theule, P., Mispelaer, F., et al. 2012, A\&A, 543, A5

Oba, Y., Watanabe, N., Kouchi, A., Hama, T., \& Pirronello, V. 2010, ApJ, 712, L174

Öberg, K. I., Garrod, R. T., Van Dishoeck, E. F., \& Linnartz, H. 2009, A\&A, 504, 891

Okabe, H. et al. 1978, Photochemistry of small molecules (New York: Wiley), 431

Schutte, W., Allamandola, L., \& Sandford, S. 1993, Icarus, 104, 118

Vinogradoff, V., Duvernay, F., Danger, G., Theulé, P., \& Chiavassa, T. 2011, A\&A, 530, A128

Wang, T., \& Bowie, J. H. 2010, Organic biomolecular chemistry, 8, 4757

Watanabe, N., \& Kouchi, A. 2002, ApJ, 571, L173

Woods, P. M., Kelly, G., Viti, S., et al. 2012, ApJ, 750, 19

Woods, P. M., Slater, B., Raza, Z., et al. 2013, ApJ, 777, 90

Wright, I., Sheridan, S., Barber, S., et al. 2015, Science, 349, aab0673

Yabushita, A., Hama, T., Iida, D., et al. 2008, ApJ, 682, L69 